\title{
Percepção e paisagem no cotidiano de escolas inseridas em paisagens rurais e urbanas
}

\section{Perception and landscape in the everyday life of schools in rural and urban areas}

\author{
Wallace Ancelmo dos Santos ${ }^{1}$ \\ https://orcid.org/0000-0002-6788-0335 \\ Ricardo Sartorello ${ }^{2}$ \\ https://orcid.org/0000-0002-6062-8268
}

\begin{abstract}
Resumo: O estudo identificou a percepção sobre meio ambiente de alunos de quatro escolas localizadas em paisagens culturais, rurais e urbanas. Na percepção dos alunos, identificada por meio de mapas mentais, há predomínio significativo de elementos naturais, bióticos e abióticos, indicando que possuem uma percepção naturalista sobre meio ambiente. Os alunos demonstram perceberem os elementos paisagísticos característicos do entorno da escola e da cidade: árvores, serras/morros/montanhas, rios e lagos/represas, evidenciando a influência da paisagem da cidade na percepção sobre meio ambiente apresentada por eles. A percepção da paisagem local, expressa pela presença desses elementos, é uma forma de leitura da paisagem construída pelos alunos a partir das experiências cotidianas com a paisagem da cidade, e, dessa forma, apresenta-se como uma alternativa a ser utilizada pelos professores para a educação ambiental a partir da leitura da paisagem em que as escolas estão inseridas.
\end{abstract}

Palavras-chave: Percepção. Meio ambiente. Leitura. Paisagem. Ensino fundamental.

\begin{abstract}
The study identified the perception of the environment by students from four schools located in cultural, rural and urban landscapes. In the students' perception, identified using mind maps, there is a significant predominance of natural, biotic and abiotic elements, which indicates a naturalistic perception of the environment. Students demonstrated a perception of characteristic elements of the landscape surrounding the school and the city: trees, hills/mountains, streams and lakes/dams, thus highlighting the influence of the city's landscape on the perception of the environment presented by them. The perception of the local landscape, expressed through daily life experiences, is a form of landscape reading constructed by the students via everyday experiences with the city's landscape, thus presenting itself as an alternative to be used by teachers for environmental education through the reading of the landscape in which the schools are inserted.
\end{abstract}

Keywords: Perception. Environmental education. Elementary school.

\footnotetext{
${ }^{1}$ Universidade Federal do Amazonas (UFAM), Instituto de Saúde e Biotecnologia, Coari, AM, Brasil. E-mail: wallacesax@ufam.edu.br

${ }^{2}$ Universidade de Mogi das Cruzes (UMC), Núcleo de Ciências Ambientais, Mogi das Cruzes, SP, Brasil.
} 


\section{Introdução}

A paisagem tem possibilidades ilimitadas (DARDEL, 1990). Uma delas é a educação ambiental a partir da percepção sobre meio ambiente como uma forma de leitura da paisagem. Dessa forma, a percepção permite a compreensão de valores e práticas sociais necessárias para redução dos problemas ambientais que o mundo enfrenta.

No artigo 5. ${ }^{\circ}$ da Política Nacional de Educação Ambiental (PNEA), tais valores e práticas sociais devem focar no “[...] desenvolvimento de uma compreensão integrada do meio ambiente em suas múltiplas e complexas relações, envolvendo aspectos ecológicos, psicológicos, legais, políticos, sociais, econômicos, científicos, culturais e éticos” (BRASIL, 1999). Essas premissas, que visam à conservação e à preservação do meio ambiente, exigem mudanças de visão e ações do ser humano sobre meio ambiente (SEEMANN, 2003) e, para isso, necessitam da educação ambiental para que elas sejam alcançadas pela sociedade (JACOBI, 2003). Assim, a percepção ambiental e a leitura da paisagem, juntas, são uma alternativa a ser utilizada.

Mormente, a visão de meio ambiente é relacionada com o significado de Natureza e até de Ecologia (AIRES; BASTOS, 2011). No entanto, Tuan (1965, p. 6, tradução nossa) lança um sentido mais amplo, conceituando meio ambiente como "[...] as condições sob as quais qualquer pessoa ou coisa vive ou se desenvolve; a soma total de influências que modificam ou determinam o desenvolvimento da vida ou do caráter".

A percepção ambiental é utilizada para identificar pontos positivos e negativos na relação entre ser humano e meio ambiente (TORRES; OLIVEIRA, 2012). Em um sentido fenomenológico, Faggionato (2005 apud MALAFAIA; RODRIGUES, 2009, p. 266) conceitua a percepção ambiental como a tomada de consciência do ser humano sobre o meio ambiente e a forma como eles se relacionam. Nessa perspectiva, a investigação da percepção ambiental torna possível compreender as diferentes percepções do ser humano sobre o meio ambiente (WHYTE, 1978). Esse momento de investigação contribui para que as pessoas reflitam suas ações (MAROTI; SANTOS; PIRES, 2000), pois, ao refletir sobre a relação com o meio ambiente, o homem busca entender seu lugar nela (MARIN; OLIVEIRA; COMAR, 2003). Ela também pode encorajar a participação das pessoas na preservação e na conservação do meio ambiente (WHYTE, 1978). Portanto, a percepção ambiental deve ser uma etapa anterior a qualquer projeto que envolva a relação entre homem e meio ambiente em atividades de educação ambiental (PEDRINI; COSTA; GHILARDI, 2010).

Pesquisadores vêm se empenhando em compreender a percepção sobre meio ambiente de grupos de alunos ressaltando a importância dessa etapa para a educação ambiental (AIRES; BASTOS, 2011; PEDRINI; COSTA; GHILARDI, 2010; SCHWARZ; SEVEGNANI; ANDRÉ, 2007; TELLES; SILVA, 2012). Profice et al. (2013) pesquisaram a percepção de alunos do Ensino Fundamental sobre meio ambiente de paisagens naturais da Mata Atlântica no sul da Bahia por meio de desenhos e entrevistas. Os resultados demonstraram a existência de proximidade dos desenhos com a realidade da paisagem local vivida pelos alunos. Garrido e Meirelles (2014) discutiram a percepção de meio ambiente de alunos do Ensino Fundamental com referência à Educação Ambiental Crítica se baseando em desenhos, entrevistas e gravuras. Os alunos apresentaram uma percepção naturalista de meio ambiente. Cantanhede et al. (2016) também analisaram a percepção ambiental por meio de desenhos elaborados por alunos do Ensino Fundamental de uma Escola de Zona Rural do entorno da Unidade de Conservação 
Federal em Chapadinha, MA. A maioria das representações foi de elementos naturais e concretos, demonstrando a relação dos estudantes com seu espaço natural e cultural. São desconhecidas pesquisas sobre percepção de meio ambiente de alunos de escolas inseridas em diferentes paisagens culturais - rurais e urbanas - que discutam a educação ambiental pautada na leitura da paisagem.

Este artigo busca compreender, por meio da percepção ambiental, como as paisagens culturais - rurais e urbanas - do entorno das escolas estudadas contribuem para construção da percepção dos alunos sobre meio ambiente. Também pretende colaborar com discussões sobre a Educação Ambiental a partir da Leitura da Paisagem.

\section{Educação Ambiental e Leitura da Paisagem}

A Educação Ambiental, a partir da Conferência Intergovernamental de Tsibilisi (na antiga União Soviética) aprofundou o processo de criação de condições para a construção de uma consciência sobre o meio ambiente e seus valores, fundamentando-o em princípios de interdisciplinaridade e transversalidade (JACOBI, 2003). Esses princípios trouxeram aplicabilidade à Educação Ambiental como um processo educativo em diversos níveis de formação por meio de ações baseadas em princípios éticos, sustentáveis, de identidade cultural e diversidade, de práticas interdisciplinares e mobilização social (SORRENTINO, 1998). Concebida como um processo educativo, a Educação Ambiental pode ser considerada uma prática social que implica ao ser humano uma relação de caráter social e ético com a natureza (TOZONIREIS, 2008). Deve ser um processo permanente de aprendizagem que resulte em cidadãos com consciência local e global dos problemas ambientais (JACOBI, 2003). Nessa perspectiva, a Educação Ambiental pode estar presente em todas as disciplinas, sem limites, com caráter interdisciplinar e de transversalidade (REIGOTA, 2017). Nesse sentido, podemos considerar a Leitura da Paisagem um recurso didático e metodológico para Educação Ambiental.

A Leitura da Paisagem permite a compreensão da complexa inter-relação entre o ser humano e o meio ambiente. Trata-se de um processo no qual os alunos buscam interpretar imagens do seu mundo vivido como parte de um processo de construção espacial e temporal. É nesse momento que os alunos podem realizar observações, registros, análises e, a partir disso, procurar explicações para problemas socioambientais (ANDRADE; FURLAN, 2011).

Ademais, a Leitura da Paisagem permite identificar, relacionar, analisar, interpretar, compreender e explicar fenômenos socioespaciais e, por meio dessas habilidades, perceber seus elementos e os problemas ambientais do bairro, da cidade, do município e de outras paisagens, além da compreensão de que estes são resultados de ações individuais ou coletivas. A Leitura da Paisagem permite ir além da descrição e estudo de um mundo concebido como estático. Tem seu enfoque na compreensão das dinâmicas das transformações, que incluem processos sociais, físicos e biológicos em pequenas ou grandes escalas (BRASIL, 1998).

No entanto, pautar a educação ambiental na leitura da paisagem exige que consideremos que a paisagem é formada por aspectos naturais e humanos cujos elementos naturais propiciam um ambiente adequado para a atividade humana (TUAN, 1983). Na Geografia Humanista, além dos aspectos físicos, a paisagem incorpora o trabalho humano como agente transformador e não apenas com o papel de espectador. Nessa vertente, há dois tipos de paisagens: a natural e a cultural. $\mathrm{Na}$ primeira, os elementos predominantes são as combinações de 
terreno, vegetação, solo, rios e lagos. Na segunda, são consideradas as modificações realizadas pelo homem, como nas áreas urbanas e rurais, incluindo o contexto geográfico, histórico e social (HOLZER, 1997).

A separação entre paisagem natural e cultural reafirma o papel do homem como agente transformador da natureza e torna possível compreender a organização do espaço e dos problemas ambientais. Dessa forma, a paisagem se torna uma materialização de ideias, determinadas por um sistema de significação entre o ambiente rural e urbano, de forma humanizada, não apenas pela ação humana sobre ela, mas também pelo pensar (SCHIER, 2003). Os aspectos objetivos e subjetivos envolvidos nas experiências com a paisagem formam uma realidade que exprimem afetividade e racionalidade ganhando novos significados e valores ao longo do tempo (GUIMARÃES, 2002; TUAN, 1983). Para Van Den Born et al. (2001), a intensidade dessas experiências na infância deixa as pessoas, quando adultas, mais abertas para uma visão de responsabilidade sobre os problemas ambientais. Essa abertura torna a paisagem um local privilegiado para aprendizagem de valores, permitindo ao homem o conhecimento da riqueza e dos problemas ambientais do lugar em que ele vive (SANDEVILLE JR., 2010; SOUSA, 2015). Para a European Landscape Convention (2014), a exploração dos valores da paisagem na Educação Ambiental pode ser ensinada a partir da Leitura da Paisagem. Essa prática exige metodologias sistematizadas de organização de processos formativos de trasmissão e apropriação crítica de valores que proporcione reflexão em níveis individuais e coletivos sobre os problemas ambientais (TOZONI-REIS, 2008).

Trabalhos apontam para este caminho, situando a Leitura da Paisagem como uma alternativa de abordagem da temática ambiental na escola se relacionando de forma direta ou indireta com a Educação Ambiental por meio da percepção ambiental, interpretação e compreensão de problemas socioambientais de um lugar (ARAÚJO; MAGALHÃES; CARDOSO, 2017; CALLAI, 2005; COVELLO, 2011; GONÇALVES, NUCCI, VALASKI, 2014; GUIMARÃES, 2010; MARTINS FILHO; SANTOS, 2011; OLIVEIRA, 2017; OLIVEIRA; PINTO; BARBOSA, 2011; PEDROTTI, 2005; PUNTEL, 2007; SILVA; CARVALHO, 2013; VERDUM; PUNTEL, 2010).

\section{Método}

Os participantes da pesquisa são 108 alunos do 5..$^{\circ}$ Ano do Ensino Fundamental de quatro escolas públicas da Cidade de Mogi das Cruzes, SP. As escolas estão localizadas em diferentes contextos de paisagens culturais, duas em paisagens rurais, classificadas como: E. P. Rural (Escola em Paisagem Rural) 1 e E. P. Rural 2, e duas em paisagens urbanas: E. P. Urbana (Escola em Paisagem Urbana) 1 e E. P. Urbana 2.

Adotou-se a classificação de Paisagem Rural e Urbana com base no mapeamento e na análise da paisagem do entorno das escolas em Buffers com raios de $1 \mathrm{~km}$ (Figura 1) realizado no software QGis 2.14.2, sobre imagens satelitais de 2015 da Digital Globe (Google), com $50 \mathrm{~cm}$ de resolução espacial do ano de 2010, disponíveis no site Geoportal do Instituto Geográfico Cartográfico (IGC) do Estado de São Paulo. 
Figura 1 - Configuração dos elementos naturais e antrópicos da paisagem do entorno das escolas inseridas em paisagens rurais (E. P. R.) e urbanas (E. P. U.) do município de Mogi das Cruzes, SP

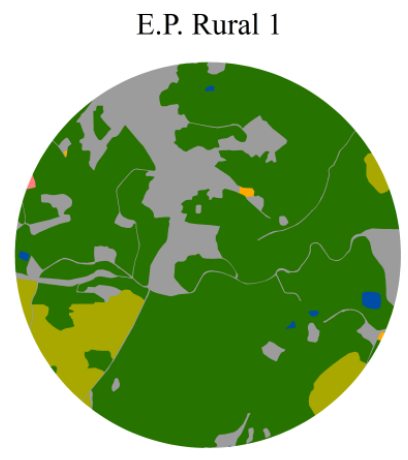

E.P. Urbana 1

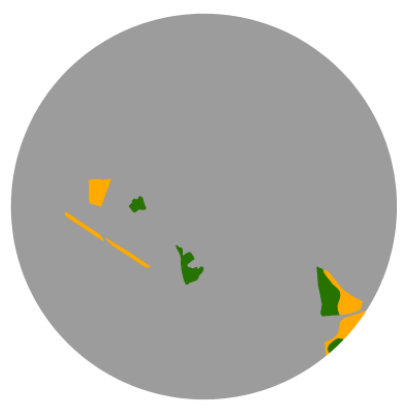

E.P. Rural 2

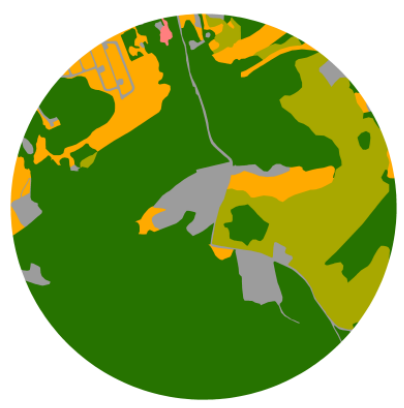

E.P. Urbana 2

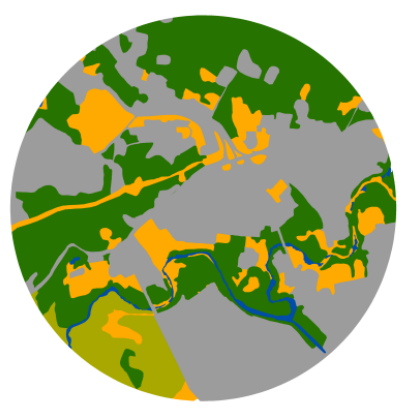

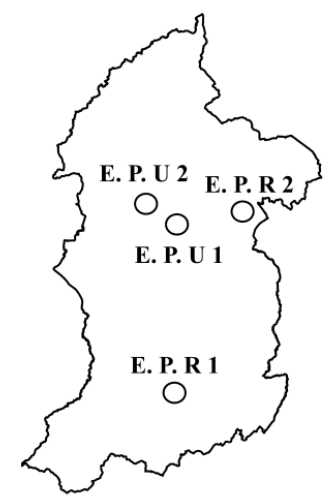

Legenda

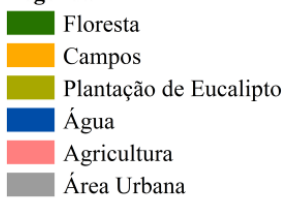

Base Cart. Digital Globe, Google Earth, 2015. Ref. Espacial; SIRGAS 2000, Proj. UTM.

Org. Wallace Ancelmo dos Santos e

Anne Karoline de Oliveira, 2017.

Laboratório de Mapeamento e

Análise da Paisagem - LabMAP.

Universidade de Mogi das Cruzes - UMC.

Fonte: elaborado pelos autores.

Os alunos dessas escolas foram pesquisados partindo da hipótese baseada em Tuan (1983), de que as experiências com paisagens rurais ou urbanas podem influenciar na percepção de meio ambiente. Desse modo, solicitou-se aos alunos que expressassem por meio de desenhos manuais em uma folha de papel A4 o que é Meio Ambiente para eles em um tempo de até 45 minutos. Durante esse tempo, buscou-se evitar interferências nas representações solicitadas aos alunos. Os desenhos manuais, neste trabalho, são denominados Mapas Mentais com base em Aires e Bastos (2011). Segundo os autores, os mapas mentais são desenhos manuais que se apresentam como ferramenta para identificar a percepção ambiental de crianças, no qual podemos desvelar as experiências do vivido, do percebido e do que é concebido sobre Meio Ambiente por elas.

Para análises dos mapas mentais, os alunos foram divididos em quatro grupos. Os mapas foram analisados de forma qualitativa e quantitativa com base em Pedrini, Costa e Ghilardi (2010), European Landscape Convention (2014) e os Parâmetros Curriculares Nacionais de Meio Ambiente e Saúde (PCN) (BRASIL, 1997). Na análise qualitativa, os símbolos desenhados que representassem algum elemento paisagístico foram classificados dentro da Categoria de Elementos Naturais (Bióticos e Abióticos) e Antropogênicos. Na análise quantitativa, o 
total de elementos encontrados em cada categoria foi analisado por meio de comparações em pares de grupos: Biótico/Abiótico, Biótico/Antropogênico e Abiótico/Antropogênico.

Também procuramos compreender as diferenças nos percentuais dos elementos por meio de comparações entre as escolas. Para isso, realizou-se o teste não paramétrico de KruskalWallis. Havendo diferenças significativas entre os grupos, realizou-se o teste de Comparações Student-Newman-Keuls. Os testes foram realizados com auxílio do software Bioestat 5.3, adotando o nível de significância de 95\%. Com base nessas análises, a percepção ambiental dos alunos foi classificada com base nas categorias de representações de meio ambiente proposta por Reigota $(1995,2007)$.

\section{Resultados e Discussão}

No geral, 108 alunos participaram do estudo. Cada aluno expressou sua percepção sobre Meio Ambiente por meio de um mapa mental (quadro 1).

Quadro 1 - Números de participantes e mapas mentais por escola

\begin{tabular}{|l|c|c|c|c|}
\hline \multirow{2}{*}{ Amostra do Estudo } & \multicolumn{2}{|c|}{ E. P. Rural 1 } & E. P. Rural 2 & \multicolumn{2}{c|}{ E. P. Urbana 1 } & E. P. Urbana 2 \\
\cline { 2 - 5 } & \multicolumn{2}{|c|}{ Escolas em Paisagem Rural } & \multicolumn{2}{|c|}{ Escolas em Paisagem Urbana } \\
\hline N. ${ }^{\text {o de Participantes }}$ & 37 & 21 & 30 & 20 \\
\hline N. ${ }^{\text {o de Mapas Mentais }}$ & 37 & 21 & 30 & 20 \\
\hline
\end{tabular}

Fonte: elaborado pelos autores a partir dos dados da pesquisa.

\section{Análise dos Mapas Mentais}

A análise qualitativa e quantitativa identificou um predomínio de Elementos Naturais - Bióticos e Abióticos - em relação aos elementos Antropogênicos nos mapas mentais das quatro escolas (Gráfico 1).

Há diferenças significativas na comparação em pares das categorias de elementos Bióticos/Abióticos (54\%/40\%, p=0,0167), Bióticos/Antropogênicos (54\%/6\%, p=0,0001), e Abióticos/Antropogênicos $(40 \% / 6 \%, \mathrm{p}=0,0001)$ na E. P. Rural 1. Na E. P. Rural 2, apenas a comparação entre as categorias Bióticos/Antropogênicos apresentou diferença significativa $(50 \% / 19 \%, \mathrm{p}=0,0031)$.

Por outro lado, nas escolas em paisagem urbana, encontrou-se diferença significativa em todas as comparações em pares: E. P. Urbana 1: Bióticos/Abióticos (51\%/35\%, $\mathrm{p}=0,0346)$, Bióticos/Antropogênicos (51\%/14\%; $\mathrm{p}=0,0001)$; e Abióticos/Antropogênicos (35\%/14\%, p=0,0013); E. P. Urbana 2: Bióticos/Abióticos (59\%/33\%, p=0,0063); Bióticos / Antropogênicos (59\%/8\%, p=0,0001); e Abióticos/Antropogênicos (33\%/8\%, p=0,0029). 
Gráfico 1 - Percentuais de elementos bióticos, abióticos e antropogênicos identificados nos mapas mentais

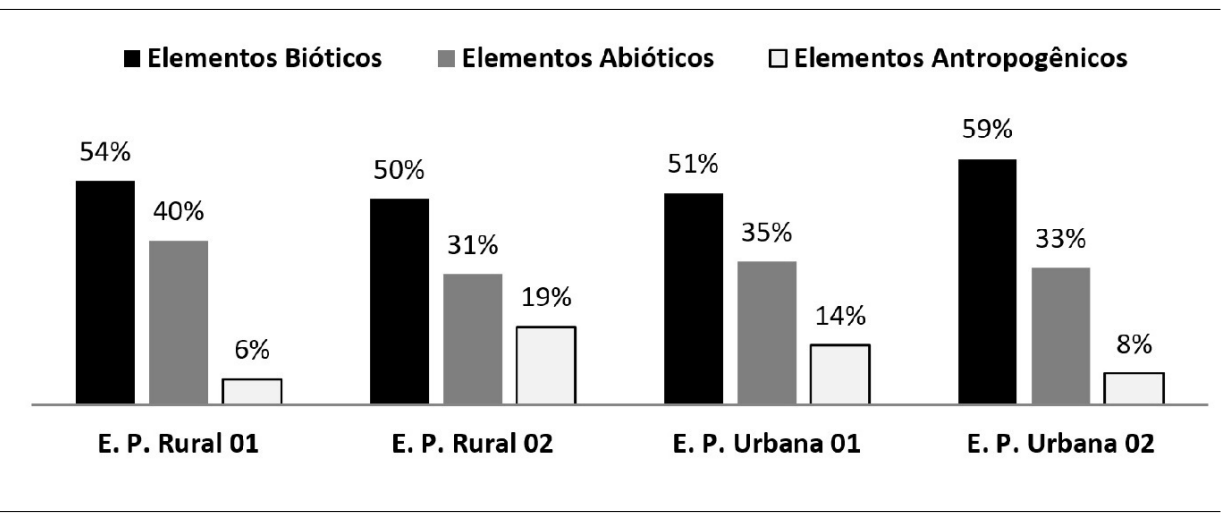

Fonte: elaborado pelos autores.

O predomínio de elementos naturais encontrado nas quatro escolas, embora não seja significativo na comparação entre elementos Bióticos/Abióticos na E. P. Rural 2, indica que a visão dos alunos sobre meio ambiente adere à concepção Naturalista, segundo a classificação de Reigota (1995, 2007), apesar de os alunos estudarem em escolas inseridas em diferentes contextos de paisagens culturais, como a rural e urbana. Para esse autor, na concepção Naturalista, existe o predomínio de elementos naturais, tais como bióticos e abióticos. Esse resultado coincide com os resultados de Aires e Bastos (2011), Pedrini, Costa e Ghilardi, (2010), Telles e Silva (2012) e Garrido e Meirelles (2014), que também encontraram uma visão Naturalista nas representações de crianças sobre meio ambiente por meio de mapas mentais. De forma geral, esse resultado sugere que os alunos, ao perceberem mais elementos naturais do que elementos antropogênicos, não relacionam o contexto da paisagem cultural em que estão inseridos com o significado de meio ambiente, onde há a presença da ação humana e, consequentemente, os problemas ambientais.

Em uma segunda análise, focamos nos elementos que formam as três categorias encontradas nos mapas mentais, pois, na medida em que eles são representados, oferecem indícios para identificação das possíveis influências das paisagens culturais, em que as escolas estão inseridas, sobre a percepção de meio ambiente dos alunos.

\section{Análise dos Elementos Bióticos}

Sete grupos de elementos foram encontrados na categoria de Elementos Bióticos nas quatro escolas: aves, animais terrestres, animais aquáticos e marinhos, árvores, arbustos, grama e flores (Tabela 1). 
Tabela 1 - Percentual das representações de Elementos Bióticos dos estudantes das escolas inseridas em Paisagem Rural e Urbana.

\begin{tabular}{lcccc}
\hline \multirow{2}{*}{ Elementos Bióticos } & E. P. Rural 1 & E. P. Rural 2 & E. P. Urbana 1 & E. P. Urbana 2 \\
\cline { 2 - 5 } & \multicolumn{2}{c}{ Escolas em Paisagem Rural } & \multicolumn{2}{c}{ Escolas em Paisagem Urbana } \\
\cline { 2 - 5 } & Frequência/\% & Frequência/\% & Frequência/\% & Frequência/\% \\
\hline Aves & $92 \%$ & $48 \%$ & $33 \%$ & $60 \%$ \\
Animais terrestres & $24 \%$ & $33 \%$ & $33 \%$ & $40 \%$ \\
Animais aquáticos e marinhos & $19 \%$ & $19 \%$ & $17 \%$ & $15 \%$ \\
Árvores & $100 \%$ & $76 \%$ & $93 \%$ & $95 \%$ \\
Arbustos & $27 \%$ & $5 \%$ & $27 \%$ & $20 \%$ \\
Grama & $73 \%$ & $33 \%$ & $63 \%$ & $65 \%$ \\
Flores & $68 \%$ & $48 \%$ & $53 \%$ & $50 \%$ \\
\hline Fyyyy
\end{tabular}

Fonte: elaborada pelos autores a partir dos dados da pesquisa.

Entre esses elementos, destacamos a diferença no percentual de presença de Aves nos desenhos dos alunos da E. P. Rural 1 em relação as E. P. Rural 2, E. P. Urbana 1 e E. P. Urbana 2 ( $p=0,0127 ; p=0,0476 ; p=0,0001$, respectivamente). Telles e Silva (2012) estudaram a percepção de crianças sobre o meio ambiente e constataram uma grande presença de pássaros em $71 \%$ dos mapas mentais, corroborando com o resultado encontrado E. P. Rural 1. Da mesma forma, Profice et al. (2013) também identificaram a presença de Aves em $80 \%$ dos mapas mentais analisados por ela e explicou o fenômeno com base em dois fatores: a de ordem estética, que induz as crianças a preencherem os espaços dos desenhos com aves; e a de ordem paisagística, relacionada ao Bioma Mata Atlântica, já que na região do estudo pode ser avistada uma grande quantidade de Aves. Segundo Pedrini, Costa e Ghilardi (2010), a presença de Aves nos mapas mentais também é justificada por eles serem mais fáceis de serem observados, seja em virtude do valor estético ou pelos sons que eles produzem. Além disso, acreditamos que a diferença encontrada entre a E. P. Rural 1, em relação às demais, está relacionada com a paisagem em que ela está inserida, onde predominam elementos naturais tanto na sua configuração como na sua composição, sendo um ambiente propício para o abrigo e a presença de Ave Fauna, podendo facilitar a observação desses animais.

Também destacamos as representações de Árvores feitas pelos alunos que, apesar de não apresentarem diferenças significativas entre as escolas, têm os maiores percentuais nessa categoria em todas elas: E. P. Rural 1 (100\%), E. P. Rural 2 (76\%), E. P. Urbana 1 (93\%) e E. P. Urbana 2 (95\%). A presença de árvores também foi identificada nos trabalhos de Aires e Bastos (2011), Garrido e Meirelles (2014), Pedrini, Costa e Ghilardi (2010), Rocha et al. (2016), e Telles e Silva (2012). Para esses autores, a presença desse elemento indica ambientes preservados e, por isso, a percepção sobre meio ambiente desses alunos tem uma concepção Naturalista. No estudo realizado por Profice et al. (2013), a alta proporção de árvores representada pelos alunos foi, assim como a presença de aves, relacionada com as características do Bioma Mata Atlântica. O mesmo fator pode estar relacionado com os resultados dessa pesquisa, onde as escolas estudadas estão inseridas em paisagens do mesmo Bioma.

Os demais elementos representados nessa categoria - animais terrestres, animais aquáticos e marinhos, arbustos, grama e flores - também não apresentaram diferenças significativas nas comparações entre as escolas. No entanto, a presença desses elementos é importante para 
a identificação da percepção ambiental desses alunos. Os trabalhos de Garrido e Meirelles (2014), Pedrini, Costa e Ghilardi (2010), Profice et al. (2013), e Telles e Silva (2012) também encontraram a presença desses elementos em seus estudos. Para esses autores, a presença deles nos mapas mentais reforça a ideia de os alunos terem uma percepção Naturalista sobre meio ambiente. Rocha et al. (2016) acrescenta que a falta ou a baixa representação desses elementos pode significar pouco contato dos alunos com a Natureza, evidenciando a necessidade de eles frequentarem ambientes naturais com mais frequência.

\section{Análise dos Elementos Abióticos}

Em relação à categoria de Elementos Abióticos, identificou-se a presença de oito elementos: sol, arco-íris, rios, cachoeiras, lagos e represas, nuvens, morros, serras e montanhas e rochas (Tabela 2).

Tabela 2 - Percentual das representações de elementos abióticos dos estudantes das escolas inseridas em Paisagem Rural e Urbana

\begin{tabular}{|c|c|c|c|c|}
\hline \multirow{3}{*}{ Elementos Abióticos } & E. P. Rural 1 & E. P. Rural 2 & E. P. Urbana 1 & E. P. Urbana 2 \\
\hline & \multicolumn{2}{|c|}{ Escolas em Paisagem Rural } & \multicolumn{2}{|c|}{ Escolas em Paisagem Urbana } \\
\hline & Frequência/\% & Frequência/\% & Frequência/\% & Frequência/\% \\
\hline Sol & $86 \%$ & $71 \%$ & $77 \%$ & $75 \%$ \\
\hline Arco-íris & $11 \%$ & $10 \%$ & $0 \%$ & $0 \%$ \\
\hline Rios & $27 \%$ & $33 \%$ & $23 \%$ & $55 \%$ \\
\hline Cachoeiras & $30 \%$ & $0 \%$ & $3 \%$ & $0 \%$ \\
\hline Lagos e represas & $22 \%$ & $0 \%$ & $13 \%$ & $0 \%$ \\
\hline Nuvens & $76 \%$ & $52 \%$ & $63 \%$ & $55 \%$ \\
\hline Morros, Serras e & $35 \%$ & $19 \%$ & $37 \%$ & $10 \%$ \\
\hline \multicolumn{5}{|l|}{ Montanhas } \\
\hline Rochas & $11 \%$ & $0 \%$ & $10 \%$ & $5 \%$ \\
\hline
\end{tabular}

Fonte: elaborada pelos autores a partir dos dados da pesquisa.

Não foram encontradas diferenças significativas entre os Elementos dessa Categoria, mas destacamos a diferença percentual na presença de cachoeiras entre a E. P. Rural $1 \mathrm{em}$ relação as E. P. Rural 2, E. P. Urbana 1 e E. P. Urbana 2 (Tabela 2). A presença de cachoeiras na E. P. Rural 1 pode estar relacionada com as características da paisagem Rural que a escola está inserida, próxima da Serra do Mar, onde existem muitas cachoeiras. Outra razão para essas representações é a presença de uma fonte natural de água dentro da área verde dessa escola, entendida pelos alunos como uma cachoeira. Também chamamos atenção para a diferença nas representações de lagos e represas apresentada na E. P. Rural 1 em relação às E. P. Rural 2, E. P. Urbana 1 e E. P. Urbana 2 (Tabela 2).

A presença de Lagos e Represas também pode estar relacionada com a paisagem em que a escola está inserida. Aires e Bastos (2011) destacaram uma grande quantidade de representações de cachoeiras e lagos presentes nos mapas mentais de alunos do ensino fundamental. O autor relacionou esse resultado com a existência desse elemento na paisagem no entorno 
da escola em que o estudo foi realizado. Acreditamos que a presença de lagos e represas também pode ter relação com a represa Jundiaí, nas proximidades da E. P. Rural.

Destacamos mais dois resultados nessa categoria: primeiro, as representações de rios, que, no caso da E. P. Urbana 2, foi a que apresentou o percentual maior entre as quatro escolas (55\%). Aires e Bastos (2011) encontraram representações de lagos nos mapas mentais e relacionaram esse resultado com o lago que margeia a cidade do estudo. Isso também pode ter ocorrido no caso dos rios nos mapas mentais da E. P. Urbana 2, pois a escola está localizada às margens do rio Tietê, um importante atributo paisagístico da cidade e da região, o que também justifica a presença nos mapas mentais das outras escolas. O segundo são as representações de Elevações do Relevo - morros, serras e montanhas - identificadas também nas quatro escolas. Quanto à presença desses elementos, Aires e Bastos (2011) relacionaram com a paisagem da região onde ocorreu o estudo, que também tem formações de relevos. No caso deste artigo, a presença de elevações de relevo nos mapas mentais pode estar relacionada com a presença de dois importantes atributos da paisagem local: a serra do Itapeti e a serra do Mar. A primeira localizada no norte e a segunda no sul da cidade, facilitando sua visualização.

Em relação às representações do elemento sol, Telles e Silva (2012) e Rocha et al. (2016) encontraram a presença de representações desse elemento nos mapas mentais analisados por eles ( $94 \%$ e $78 \%$; respectivamente); percentuais que se assemelham aos encontrados nas quatro escolas deste estudo (E. P. Rural 1, 86\%; E. P. Rural 2, 71\%; E. P. Urbana 1, 77\%; E. P. Urbana 2, 70\%). Pedrini, Costa e Ghilardi (2010), ao identificarem esse elemento, indicaram que ele pode estar relacionado com a paisagem natural, onde é mais fácil observar o sol. Ressaltamos que as representações de nuvens e arco-íris encontradas neste artigo também podem ter relação com esse fator.

\section{Análise dos Elementos Antropogênicos}

$\mathrm{Na}$ categoria de Elementos Antropogênicos, identificamos a representação de nove grupos de elementos: homem, poluição, lixeiras, placas de sinalização, ambientes construídos, semáforos, veículos de transporte, agricultura e animais domésticos (Tabela 3).

Tabela 3 - Percentual das representações de Elementos Antropogênicos dos estudantes das escolas inseridas em Paisagem Rural e Urbana

\begin{tabular}{|c|c|c|c|c|}
\hline \multirow{3}{*}{$\begin{array}{c}\text { Elementos } \\
\text { Antropogênicos }\end{array}$} & E. P. Rural 1 & E. P. Rural 2 & E. P. Urbana 1 & E. P. Urbana 2 \\
\hline & \multicolumn{2}{|c|}{ Escolas em Paisagem Rural } & \multicolumn{2}{|c|}{ Escolas em Paisagem Urbana } \\
\hline & Frequência/\% & Frequência/\% & Frequência/\% & Frequência/\% \\
\hline Homem & $19 \%$ & $33 \%$ & $27 \%$ & $20 \%$ \\
\hline Poluição & $5 \%$ & $29 \%$ & $7 \%$ & $10 \%$ \\
\hline Lixeiras & $8 \%$ & $14 \%$ & $23 \%$ & $5 \%$ \\
\hline Placas de sinalização & $5 \%$ & $14 \%$ & $23 \%$ & $5 \%$ \\
\hline Ambientes construídos & $14 \%$ & $19 \%$ & $17 \%$ & $0 \%$ \\
\hline Semáforos & $0 \%$ & $5 \%$ & $0 \%$ & $0 \%$ \\
\hline Veículos de transporte & $0 \%$ & $5 \%$ & $0 \%$ & $0 \%$ \\
\hline Agricultura & $5 \%$ & $19 \%$ & $3 \%$ & $0 \%$ \\
\hline Animais domésticos & $3 \%$ & $5 \%$ & $3 \%$ & $0 \%$ \\
\hline
\end{tabular}

Fonte: elaborada pelos autores a partir dos dados da pesquisa. 
Não encontramos diferenças significativas nas representações dos elementos entre as escolas nessa categoria. Porém, destacamos a baixa presença do homem nos desenhos em relação a outros estudos (Tabela 3). Pedrini, Costa e Ghilardi (2010) também identificaram a presença do homem em 45,4\% dos mapas analisados por eles, percentual que os autores consideraram baixa. Telles e Silva (2012) encontraram a representação de humanos em seu estudo, mas destacaram que, em relação aos elementos naturais, a presença deles não foi significativa. Já Aires e Bastos (2011) e Garrido e Meirelles (2014) constataram a inexistência desse elemento em seus estudos e concluíram que a grande maioria dos alunos tinha uma visão de meio ambiente conservacionista e sinônimo de Natureza, que não considera os aspectos políticos, culturais, sociais e econômicos envolvidos na questão ambiental, enfocando apenas nos aspectos naturais. Esses resultados corroboram com a visão naturalista sobre meio ambiente apresentada pelos pesquisadores neste artigo.

Dentre os demais elementos, destacamos a lixeira e a poluição. É interessante salientar que a presença de placas de sinalização neste artigo está, em grande parte, relacionada com lixeira e poluição, trazendo mensagens de preservação e conservação do meio ambiente. Para Aires e Bastos (2011), a presença de lixeira pode estar relacionada à prática pedagógica dos professores, já que o tema faz parte do currículo escolar e da prática pedagógica dos professores em relação à educação ambiental. Também destacamos a baixa presença dos ambientes construídos. Telles e Silva (2012) encontraram um percentual muito maior que os encontrados nas quatro escolas (31\%), mesmo assim, o autor não considerou esse resultado representativo. Isso indica que a taxa de ambientes construídos, encontrada neste trabalho, deva ser considerada baixa, fator que fortalece a necessidade de os professores trabalharem ainda mais os aspectos culturais envolvidos nas questões ambientais na educação ambiental em sala de aula.

A percepção dos alunos sobre os elementos da paisagem, tanto os naturais como os antropogênicos, é uma ferramenta a ser utilizada na educação ambiental pautada na Leitura da Paisagem. Segundo Panizza (2014), a leitura da paisagem tem papel importante na forma como o homem percebe e desvenda um novo olhar sobre as inter-relações que existe entre ele e meio ambiente. Nesse sentido, é fundamental que o professor incentive esse novo olhar (MEYER, 1991) trabalhando a consciência da responsabilidade sobre o meio ambiente (SANTOS; BONINI; SARTORELLO, 2017). Diante disso, a leitura da paisagem, como base para a educação ambiental, pode ser um meio de traçar caminhos para uma representação globalizante sobre meio ambiente, que, segundo Reigota (1991), é onde as relações entre sociedade e natureza são reconhecidas. Dessa forma, a leitura da paisagem possivelmente contribuirá na construção do pensamento crítico, defendido por Gadotti (2000), que alicerça a educação ambiental com uma perspectiva global dos problemas ambientais como um construto da relação entre o ser humano e natureza.

\section{Considerações finais}

Por meio da análise qualitativa e quantitativa dos resultados obtidos nos mapas mentais, identificamos e comparamos a percepção ambiental dos alunos de escolas inseridas em diferentes contextos de paisagens culturais.

A percepção Naturalista prevaleceu nos mapas mentais dos alunos das quatro escolas pesquisadas mesmo que em contextos distintos. Esse fato, inicialmente, conduziu-nos à 
hipótese de que esses alunos poderiam apresentar diferentes percepções sobre meio ambiente, já que as experiências com áreas naturais e construídas poderiam influenciar nesse processo de construção, o que não foi corroborado neste artigo.

Apesar de os alunos das quatro escolas apresentarem uma percepção naturalista de meio ambiente, as representações de rios, árvores, morros, serras e montanhas, e, lagos e represas, sugerem que os alunos têm afetividade com os elementos naturais da paisagem do entorno da escola em que estudam e da cidade em que moram, demonstrando a importância de se trabalhar os valores da paisagem local.

Destacamos como os elementos naturais - bióticos e abióticos - predominaram nas representações dos alunos e como os elementos antropogênicos não foram representados na mesma proporção, indicando que a compreensão dos alunos está distante - quando tratam das representações de meio ambiente -, dos aspectos culturais, políticos e sociais que envolvem os problemas ambientais que sofremos atualmente com a falta de preservação e conservação do meio ambiente por grande parte da sociedade.

A percepção Naturalista permite reforçar a necessidade de os professores desses alunos trabalharem esses aspectos quando tratarem os problemas ambientais em atividades de educação ambiental. Acreditamos que esse caminho levará os alunos a um pensamento crítico sobre os problemas ambientais que assolam nosso planeta e, a partir disso, eles adquiram uma nova postura com valores e práticas sociais para preservar e conservar os recursos naturais, conforme preconiza a Política Nacional de Educação Ambiental (PNEA).

Entendemos que a percepção dos atributos da paisagem local, rural ou urbana, também apontam caminhos para uma educação ambiental calcada na leitura da paisagem em que os alunos estão inseridos, pois, nessa leitura, as modificações que resultam da relação entre homem e meio ambiente formam a estrutura central de estudo, levando aos alunos uma visão global e crítica dos problemas ambientais que existem hoje e dos que poderão vir a existir no futuro, caso não haja uma mudança na postura da sociedade frente à crise ambiental.

Nesse sentido, a paisagem apresenta relação direta com a educação ambiental, mas necessita de uma leitura sistemática da paisagem como metodologia de estudo das transformações e dos problemas ambientais. No entanto, não se espera que a educação ambiental baseada na leitura da paisagem possibilite aos alunos o conhecimento pleno da paisagem, mas que, por meio dela, os alunos tenham uma visão ampla e crítica das inter-relações entre elementos bióticos, abióticos e ações antrópicas sobre o meio ambiente.

Essa abordagem permite uma nova possibilidade para alcançar uma sociedade consciente e crítica das mudanças que ocorrem no mundo e dos problemas que elas podem gerar para qualidade de vida, bem-estar, preservação e conservação do meio ambiente. Portanto, a percepção de meio ambiente apresentada pelos alunos pode ser considerada uma forma de leitura da paisagem e, desse modo, uma alternativa metodológica a ser utilizada pelos professores para a educação ambiental pautada na leitura da paisagem.

A leitura da paisagem pode ser explorada em diversas situações do cotidiano do aluno, aproveitando as experiências e vivências dos locais onde residem e circulam com mais frequência, assim como por meio de estímulos visuais, fotografias, pinturas, desenhos, filmes, etc.; e outros estímulos sensoriais como tato e audição. Os trabalhos de campos direcionados, quando houver essa possibilidade ou viabilidade de atividade escolar, podem complementar o olhar dos alunos sobre os diferentes elementos, composições, estruturas, funções e dinâmica 
da paisagem, proporcionando ao aluno um olhar mais maduro e consciente sobre o seu meio ambiente, base para qualquer transformação social.

\section{Referências}

AIRES, B. F. C.; BASTOS, R. P. Representações sobre meio ambiente de alunos da educação básica de Palmas (TO). Ciência \& Educação, Bauru, v. 17, n. 2, p. 353-364, 2011. DOI: https://doi.org/10.1590/S1516-73132011000200007.

ANDRADE, J. P.; FURLAN, S. A. Programa MAPA de educação, geografia e meio ambiente. Revista Geográfica de América Central, Heredia, v. 2, n. 47E, p. 1-14, 2011. Disponível em: https://www.revistas.una.ac.cr/index.php/geografica/issue/view/219. Acesso em: 9 out. 2019.

ARAÚJO, A. R. O.; MAGALHÃES, S. S. P.; CARDOSO, U. D. Geografia e educação ambiental no bairro de Águas Lindas em Belém e Ananindeua-PA. Revista IHGP, Belém, v. 3, n. 1, p. 51-70, 2017. Disponível em: http://www.ihgp.net.br/revista/index.php/revista/ article/view/53/pdf_48. Acesso em: 9 out. 2019.

BRASIL. Lei no 9.795, de 27 de abril de 1999. Dispõe sobre a educação ambiental, institui a política nacional de educação ambiental e dá outras providências. Diário Oficial, Brasília, 28 abr. 1999. Disponível em: http://portal.mec.gov.br/secad/arquivos/pdf/ educacaoambiental/lei9795.pdf. Acesso em: 30 nov. 2017.

BRASIL. Ministério da Educação e do Desporto. Parâmetros curriculares nacionais: meio ambiente saúde. Brasília: MEC, 1997. v. 9. Disponível em: http://portal.mec.gov.br/seb/ arquivos/pdf/livro091.pdf. Acesso em: 9 out. 2019.

BRASIL. Ministério da Educação e do Desporto. Parâmetros curriculares nacionais: terceiro e quarto ciclos do ensino fundamental: geografia. Brasília: MEC, 1998. Disponível em: http://portal.mec.gov.br/seb/arquivos/pdf/geografia.pdf. Acesso em: 9 out. 2019.

CALLAI, H. C. Aprendendo a ler o mundo: a geografia nos anos iniciais do ensino fundamental. Cadernos Cedes, Campinas, v. 25, n. 66, p. 227-247, 2005. DOI: https://doi. org/10.1590/S0101-32622005000200006.

CANTANHEDE, A. M.; SILVA, R. L.; SILVA, H. A.; BORGES, T. C. Análise da percepção ambiental, por meio de desenhos, de alunos do ensino fundamental numa escola da zona rural, Chapadinha-MA. Revista da SBEnBio, Niteroi, n. 9, p. 6561-6570, 2016. Disponível em: https://sbenbio.org.br/wp-content/uploads/edicoes/revista_sbenbio_n9.pdf. Acesso em: 9 out. 2019.

COVELLO, C. A paisagem de Itapema: estudo da geodiversidade para a educação ambiental e o geoturismo. 2011. 174 f. Dissertação (Mestrado em Geografia) - Universidade Federal de Santa Catarina, Florianópolis, 2011.

DARDEL, É. L'homme et la terre: nature de la réalité géographique. Paris: CTHS, 1990. 
EUROPEAN landscape convention: 1st meeting of the working group on landscape and education. Strasbourg: Council of Europe, 2014. Disponível em: https://rm.coe. int/16802fd026. Acesso em: 9 out. 2019.

GADOTTI, M. Pedagogia da terra. São Paulo: Fundacão Peirópolis, 2000.

GARRIDO, L. S.; MEIRELLES, R. M. S. Percepção sobre meio ambiente por alunos das séries iniciais do ensino fundamental: considerações à luz de Marx e de Paulo Freire. Ciência \& Educação, Bauru, v. 20, n. 3, p. 671-685, 2014. DOI: https://doi.org/10.1590/151673132014000300010 . Acesso em: 30 nov. 2017.

GONÇALVES, F. T.; NUCCI, J. C.; VALASKI, S. Educação ambiental e o planejamento da paisagem. Ambiente \& Educação, Rio Grande, v. 19, n. 1, p. 77-95, 2014.

GUIMARÃES, S. T. L. Reflexões a respeito da paisagem vivida, topofilia e topofobia à luz dos estudos sobre experiência, percepção e interpretação ambiental. Geosul, Florianópolis, v. 17, n. 33, p. 117-142, 2002.

GUIMARÃES, S. T. L. Trilhas interpretativas e vivências na natureza: aspectos relacionados à percepção e interpretação da paisagem. Caderno de Geografia, Belo Horizonte, v. 20, n. 34, p. 8-19, 2010.

HOLZER, W. Uma discussão fenomenológica sobre os conceitos de paisagem e lugar, território e meio ambiente. Território, Rio de Janeiro, n. 3, p. 77-85, 1997.

JACOBI, P. Educação ambiental, cidadania e sustentabilidade. Cadernos de Pesquisa, São Paulo, v. 118, p. 189-206, 2003. DOI: https://doi.org/10.1590/S0100-15742003000100008.

MALAFAIA, G.; RODRIGUES, A. S. L. Percepção ambiental de jovens e adultos de uma escola municipal de ensino fundamental. Revista Brasileira de Biociências, Porto Alegre, v. 7, n. 3, p. 266-274, 2009.

MARIN, M.; OLIVEIRA, H. T.; COMAR, V. A educação ambiental num contexto de complexidade do campo teórico da percepção. Interciência, Caracas, v. 28, n. 10, p. 616-619, 2003.

MAROTI, P. S.; SANTOS, J. E.; PIRES, J. S. R. Percepção ambiental de uma unidade de conservação por docentes do ensino fundamental. In: SANTOS, J. E.; PIRES, J. S. R. (org.). Estudos integrados em ecossistemas: estação ecológica de Jataí. São Carlos: Rima, 2000. v. 1, p. 207-217.

MARTINS FILHO, T. R.; SANTOS, I. P. F. A paisagem como instrumento de contextualização dos problemas ambientais no ensino da geografia no colégio militar Tiradentes, São Luis-MA. Revista Geográfica de América Central, San Jose, v. 2, n. 47E, p. 1-9, 2011.

MEYER, M. A. A. Educação ambiental: uma proposta pedagógica. Em Aberto, Brasília, v. 10, n. 49, p. 41-46, 1991. 
OLIVEIRA, D. J. S.; PINTO, H. M.; BARBOSA, R. P. Paisagem e educação ambiental no Brasil: impressões de alunos do colégio municipal professora Didi Andrade, Itabira / Brasil. The Journal of Field Actions Science Reports, special issue 3, p. 1-9, 2011. Disponível em: https://journals.openedition.org/factsreports/1536. Acesso em: 9 out. 2019.

OLIVEIRA, H. Q. A paisagem como elemento integrador no processo de ensinoaprendizagem: uma experiência em contexto de visita de estudo. Revista de Educação Geográfica UP, Porto, n. 2, p. 49-58, 2017. DOI: https://doi.org/10.21747/GeTup/2a5.

PANIZZA, A. C. Como eu ensino a paisagem. São Paulo: Saraiva, 2014.

PEDRINI, A.; COSTA, E. A.; GHILARDI, N. Percepção ambiental de crianças e préadolescentes em vulnerabilidade social para projetos de educação ambiental Socially vulnerable children and pre-adolescents. Ciência \& Educação, Bauru, v. 16, n. 1, p. 163-179, 2010. DOI: https://doi.org/10.1590/S1516-73132010000100010.

PEDROTTI, D. E. Educação e paisagem: tecendo elos para educação. 2005. 86 f. Dissertação (Mestrado em Educação) - Instituto de Educação, Universidade Federal de Mato Grosso, Cuiabá, 2005.

PROFICE, C.; PINHEIRO, J. Q.; FANDI, A. C.; GOMES, A. R. Janelas para a percepção infantil de ambientes naturais. Psicologia em Estudo, Maringá, v. 18, n. 3, 2013. DOI: https://doi.org/10.1590/S1413-73722013000300014.

PUNTEL, G. A paisagem no ensino da geografia. Ágora, Vitória, v. 13, n. 1, p. 283-298, 2007. REIGOTA, M. A. S. Meio ambiente e representação social. São Paulo: Cortez, 1995. REIGOTA, M. A. S. Meio Ambiente e representação social. 7. ed. São Paulo: Cortez, 2007.

REIGOTA, M. A. S. O meio ambiente e suas representações no ensino em São Paulo, Brasil. Uniambiente, São Paulo, v. 2, n. 1, p. 27-30, 1991.

REIGOTA, M. A. S. O que é educação ambiental. São Paulo: Brasiliense, 2017.

ROCHA, A. G. S.; GHENO, S.; GONÇALVES, F. C. L.; DAL-FARRA, R. A. Educação infantil: articulando a produção de desenhos com a educação ambiental em uma escola comunitária do sul do Brasil. Revista Ibero-ameriana de Educación, Madrid, v. 72, p. 183206, 2016. DOI: https://doi.org/10.35362/rie72042.

SANDEVILLE JR., E. A paisagem do município como território educativo. In: PADILHA, P. R.; CECCON, S.; RAMALHO, P. (org.). Município que educa: múltiplos olhares. São Paulo: Ed,L: UniFreire, 2010. p. 81-86.

SANTOS, W. A.; BONINI, L. M. M.; SARTORELLO, R. Contribuições da paisagem rural e urbana para práticas pedagógicas de educação ambiental. Fórum Ambiental da Alta Paulista, Tupã, v. 13, n. 4, p. 94-98, 2017. DOI: https://doi.org/10.17271/19800827134201 71702.

SCHIER, R. A. Trajetórias do conceito de paisagem na geografia. RA'EGA, Curitiba, n. 7, p. 79-85, 2003. DOI: https://doi.org/10.5380/raega.v7i0.3353. 
SCHWARZ, M. L.; SEVEGNANI, L.; ANDRÉ, P. Representações da Mata Atlântica e de sua biodiversidade por meio dos desenhos infantis. Ciência \& Educação, Bauru, v. 13, n. 3, p. 369-388, 2007. DOI: https://doi.org/10.1590/S1413-73722013000300014.

SEEMANN, J. Mapas e percepção ambiental: do mental ao material e vice-versa. OLAM: ciência \& tecnologia, Rio Claro, v. 3, n. 1, p. 200-223, 2003.

SILVA, K. O.; CARVALHO, M. V. C. Meio ambiente e o ensino de geografia: percepção do aluno sobre educação ambiental. Revista de Geografia, Recife, v. 30, n. 2, p. 169-188, 2013.

SORRENTINO, M. De Tbilisi a Tessalonique, a educação ambiental no Brasil. In: CASCINO, F.; OLIVEIRA, J. F.; JACOBI, P. (org.). Educação, meio ambiente e cidadania: reflexões e experiências. São Paulo: SMA, 1998. p. 20-24.

SOUSA, J. A. Paisagem como ferramenta metodológica para o ensino da categoria geográfica paisagem. Pesquisar: revista de estudos e pesquisas em ensino de geografia, Florianópolis, v. 2, n. 3, p. 20-30, 2015. Disponível em: http://incubadora.periodicos.ufsc.br/index.php/ pesquisar/article/view/3664. Acesso em: 30 nov. 2017.

TELLES, C. A.; SILVA, G. L. F. Relação criança e meio ambiente: avaliação da percepção ambiental através da análise do desenho infantil. TechnoEng, Ponta Grossa, n. 6, p. 1-26, 2012.

TORRES, D. F; OLIVEIRA, E. S. Percepção ambiental: instrumento para educação ambiental em unidades de conservação. REMEA: revista eletrônica do mestrado em educação ambiental, Rio Grande, v. 21, p. 227-235, 2012.

TOZONI-REIS, M. F. C. Metodologias aplicadas à educação ambiental. Curitiba: IESD Brasil, 2008.

TUAN, Y. F. "Environment" and "world”. The Professional Geographer, Philadelphia, v. 17, n. 5, p. 6-8, 1965. DOI: https://doi.org/10.1111/j.0033-0124.1965.006_q.x.

TUAN, Y. F. Espaço e lugar: a perspectiva da experiência. São Paulo: DIFEL, 1983.

VAN DEN BORN, R. J. G.; LENDERS, R. H. J.; GROOT, W. T.; HUIJSMAN, E. The new biophilia: an exploration of visions of nature in western countries.

Environmental Conservation, v. 28, n. 1, p. 65-75, 2001. DOI: https://doi.org/10.1017/ S0376892901000066.

VERDUM, R.; PUNTEL, G. A. Espaço geográfico e paisagem. In: GEOGRAFIA: ensino fundamental. Brasília: Ministério da Educação, 2010. p. 75-88.

WHYTE, A. V. T. La perception de l'environnement: lignes directives méthodologiques pour les études sur le terrain. Paris: Unesco, 1978. Disponível em: https://unesdoc.unesco. org/ark:/48223/pf0000024707_fre. Acesso em: 10 out. 2019.

Recebido em: 21/09/2018. Aceito em: 16/05/2019

Contato: Instituto de Saúde e Biotecnologia de Coari, Estrada Coari

Mamia, Espirito Santo, 305, Coari, AM, 69460-000, Brasil. 